\title{
Physiological correlates of ecological divergence along an urbanization gradient: differential tolerance to ammonia among molecular forms of the malaria mosquito Anopheles gambiae
}

Billy Tene Fossog ${ }^{1,2,3}$, Christophe Antonio-Nkondjio ${ }^{2}$, Pierre Kengne ${ }^{1,2}$, Flobert Njiokou ${ }^{3}$, Nora J Besansky ${ }^{4}$ and Carlo Costantini ${ }^{1,2^{*}}$

\begin{abstract}
Background: Limitations in the ability of organisms to tolerate environmental stressors affect their fundamental ecological niche and constrain their distribution to specific habitats. Evolution of tolerance, therefore, can engender ecological niche dynamics. Forest populations of the afro-tropical malaria mosquito Anopheles gambiae have been shown to adapt to historically unsuitable larval habitats polluted with decaying organic matter that are found in densely populated urban agglomerates of Cameroon. This process has resulted in niche expansion from rural to urban environments that is associated with cryptic speciation and ecological divergence of two evolutionarily significant units within this taxon, the molecular forms $\mathrm{M}$ and $\mathrm{S}$, among which reproductive isolation is significant but still incomplete. Habitat segregation between the two forms results in a mosaic distribution of clinally parapatric patches, with the $\mathrm{M}$ form predominating in the centre of urban agglomerates and the $\mathrm{S}$ form in the surrounding rural localities. We hypothesized that development of tolerance to nitrogenous pollutants derived from the decomposition of organic matter, among which ammonia is the most toxic to aquatic organisms, may affect this pattern of distribution and process of niche expansion by the $M$ form.

Results: Acute toxicity bioassays indicated that populations of the two molecular forms occurring at the extremes of an urbanization gradient in Yaounde, the capital of Cameroon, differed in their response to ammonia. The regression lines best describing the dose-mortality profile differed in the scale of the explanatory variable (ammonia concentration log-transformed for the $\mathrm{S}$ form and linear for the $\mathrm{M}$ form), and in slope (steeper for the $\mathrm{S}$ form and shallower for the $\mathrm{M}$ form). These features reflected differences in the frequency distribution of individual tolerance thresholds in the two populations as assessed by probit analysis, with the $\mathrm{M}$ form exhibiting a greater mean and variance compared to the $\mathrm{S}$ form.

(Continued on next page)
\end{abstract}

\footnotetext{
* Correspondence: carlo.costantini@ird.fr

${ }^{1}$ Institut de Recherche pour le Développement (IRD), Unité Mixte de Recherche MIVEGEC (UM1, UM2, CNRS 5290, IRD 224), Montpellier, France ${ }^{2}$ Laboratoire de Recherche sur le Paludisme, Organisation de Coordination pour la lutte contre les Endémies en Afrique Centrale (OCEAC), Yaounde, Cameroon

Full list of author information is available at the end of the article
} 
(Continued from previous page)

Conclusions: In agreement with expectations based on the pattern of habitat partitioning and exposure to ammonia in larval habitats in Yaounde, the $\mathrm{M}$ form showed greater tolerance to ammonia compared to the $\mathrm{S}$ form. This trait may be part of the physiological machinery allowing forest populations of the $\mathrm{M}$ form to colonize polluted larval habitats, which is at the heart of its niche expansion in densely populated human settlements in Cameroon.

Keywords: Local adaptation, Fundamental ecological niche, Environmental stressor, Evolution of tolerance, Urbanization, Malaria, Mosquito

\section{Background}

A central theme in evolutionary ecology is understanding the origin and maintenance of adaptations shaped by natural selection. Adaptations result from micro-evolutionary processes occurring within the constraints of the evolutionary dynamics of the fundamental ecological niche, hence understanding such dynamics is crucial to understand the nature and dynamics of adaptations [1]. Physiological limits occur when abiotic conditions become stressful to the extent that organisms fail to survive and reproduce [2], and therefore play a crucial role in determining the fundamental ecological niche and biogeography of organisms (e.g. [3]). In an evolutionary context, abiotic environmental stressors (hereafter, stressors, as a shorthand) constrain the ability of organisms to adapt to environmental changes [4]. Stressors operate not only globally, e.g. in response to climate change across time $[5,6]$ or space (e.g. [7-10]), but also on a local scale in association to geographical heterogeneities (e.g. altitudinal gradients $[11,12])$, or spatial changes in landscape patterns due to e.g. urbanization or salinisation [13-15]. Accumulation of toxic compounds derived from natural or anthropogenic sources can prevent the occurrence and growth of a species in contaminated areas until the emergence and spread of tolerant genotypes allow colonization of such otherwise unsuitable habitats-a case of ecological niche expansion-which is a phenomenon well known in plants that have adapted to grow in soils contaminated by heavy metals [16].

Populations of the most important malaria vector in tropical Africa, i.e. Anopheles gambiae sensu stricto, offer instances of recent niche expansion $[17,18]$ that can provide us with insights about the ecological and molecular mechanisms underlying the emergence and maintenance of adaptations. Niche expansion in An. gambiae has resulted in ecological and genetic divergence associated to cryptic speciation of two evolutionarily significant units within this mosquito, named molecular forms $\mathrm{M}$ and $\mathrm{S}$, among which reproductive isolation is strong but still incomplete $[19,20]$. In view of greater genetic similarity of $\mathrm{S}$ with the ancestral species of the complex $A n$. arabiensis [21-24], it is postulated that the $S$ form is ancestral and the derived $M$ form has emerged through a process of ecological speciation that is still underway [17]. The molecular forms of An. gambiae inhabit most eco-climatic domains of their distribution range in West and Central Africa, occurring from xeric steppes and dry savannas at higher latitudes to the Guineo-Congolian rainforest block at lower latitudes [25]. Some ecological divergence, however, is manifested in habitat segregation between the two forms over large geographical extents, with clinal changes in relative abundance resulting in predominance of the $M$ form in marginal environments like coastal and more xeric habitats [17,26-28].

Some evidence suggests that a process of inter-form competition is driving the process of niche expansion [17]. As populations of both $\mathrm{M}$ and $\mathrm{S}$ are chromosomally $[17,25,28,29]$ and molecularly [23,30,31] distinct between savanna and forest, it is perhaps not surprising that niche expansion of the $M$ form has followed different pathways in these two eco-climatic domains. In the savanna of Burkina Faso and Mali, niche expansion is manifested in the occupation by the $M$ form of habitats [17] and seasons $[32,33]$ of marginal quality, including anthropogenic larval breeding sites of a more stable and complex nature [34], where mosquito predators are more abundant [35]. In the rainforest of Cameroon, the $M$ form has evolved adaptations enabling it to live in urban agglomerates, where its larvae can develop in water collections polluted with decaying organic matter and inorganic waste that occur in slums and other densely populated urban habitats [18]. In Yaounde, where this phenomenon has been observed and described with some degree of detail, niche expansion is manifested in clinal patterns of habitat segregation along urbanization gradients. In this city, it is only the $M$ form that has adapted to breed in polluted anthropogenic water collections. Accordingly, in the forest eco-climatic domain of southern Cameroon this form occurs in the core of urban agglomerates, whereas the $\mathrm{S}$ form lives in the surrounding rural settings. The two forms meet and co-exist in sympatry in peri-urban areas where their abundance changes clinally along the urbanization gradient [18].

What factors are responsible for this pattern of habitat segregation underlying niche expansion by forest populations of the $\mathrm{M}$ form? Adaptations underlying niche evolution have presumably followed large-scale global 
phenomena like deforestation and urbanization, which are known to alter profoundly the bionomics and composition of mosquito communities in the tropics [36-38]. Thus, some hints come from observations in Cameroon that the process of niche expansion by An. gambiae has produced a novel species association with Culex quinquefasciatus, a mosquito pest that can develop in nutrient-rich waters produced by human sewage, such as cesspits or open-air waste drains [39], for which there were no previous historical records in Central Africa [40-42]. We postulated, therefore, that the $M$ form might have developed increased tolerance to those environmental stressors that historically prevented the cooccurrence of An. gambiae and Cx quinquefasciatus in the same larval habitats. Of manifold environmental stressors occurring in urban aquatic habitats, municipal and domestic waste waters contain large amounts of dissolved nitrogenous pollutants resulting from the decomposition of organic waste matter, industrial processes, agricultural runoff, and sewage effluents, which are more concentrated in Cx quinquefasciatus breeding sites [43]. Fertilisers are another source of nitrogenous compounds that can accumulate in residual irrigation water. In Yaounde and Douala, the two major towns of Cameroon where the $\mathrm{M}$ form dominates [18], cultivation of market-garden vegetables is common practice in cleared patches interspersed with urban infrastructures, and An. gambiae larvae breed in the irrigated furrows of these cultivations. Among nitrogenous compounds, ammonia (in its unionised form $\mathrm{NH}_{3}$ ) is the most toxic to fish and aquatic invertebrates $[44,45]$, and its average concentration is significantly higher in urban vs. rural larval habitats where An. gambiae preimaginal stages are found [46]. Moreover, within the urban habitat, ammonia is more concentrated in polluted as compared to unpolluted breeding sites [47].

In view of the above, we predicted that the $M$ form might have developed increased tolerance to ammonia matching the higher concentration of this compound in its core habitat. To test this expectation, we submitted $A n$. gambiae larvae to acute toxicity assays in order to assess the shape and parameters of the functional dose-mortality response under exposure to increasing ammonia concentrations. For this purpose, we tested populations of the $M$ and $\mathrm{S}$ forms from localities situated on a transect spanning a gradient of urbanization, where habitat segregation between the two molecular forms was originally recorded [18]. We report the results of these acute toxicity assays and show that the $\mathrm{M}$ form, as expected, exhibits greater tolerance to ammonia compared to the $\mathrm{S}$ form.

\section{Methods}

\section{Mosquito populations}

Mosquito larvae were collected at the two extremes of a geographic transect along an urbanization gradient in
Yaounde, the capital of Cameroon (localities 1-5 and localities 14-16 shown in Figure 1E of reference [18], where the $\mathrm{S}$ and $\mathrm{M}$ forms, respectively, largely predominate), and from two additional localities, one in the urban centre (M-site, Voirie Municipale: 351'23”N 1131'00”E), and another at the northern outskirts of Yaounde (S-site, Nkolondom: $3^{\circ} 57^{\prime} 23^{\prime \prime} \mathrm{N} 11^{\circ} 29^{\prime} 18^{\prime \prime E}$ ), which were selected to increase the sample size and the physiognomical diversity of larval breeding sites. A sub-sample of 254 larvae exposed in the bioassays was molecularly identified to verify that sites were representative of alternative molecular forms, as expected from results of previous surveys [18]. Indeed, molecular identification by a PCR-RFLP protocol [48] confirmed that larvae collected from $M$ and $S$ sites could be considered representative of, respectively, $M$ and $\mathrm{S}$ populations. Forty individual breeding sites (21 from $\mathrm{M}$ sites, and 19 from $\mathrm{S}$ sites) were tested, for a total of 1,917 exposed larvae (1,017 from M sites and 900 from S sites).

\section{Physico-chemical properties of natural larval habitats}

To investigate differences in some physico-chemical properties of natural An. gambiae larval habitats, ammonia concentration (mg. $\mathrm{L}^{-1}$ total- $\left.\mathrm{N}\right), \mathrm{pH}$, and temperature of the breeding sites from which test larvae were collected were measured using a portable testing kit (CP1000, Wagtech International, Thatcham, Berkshire, UK).

\section{Bioassay protocol}

Ammonia acute toxicity assays followed procedures similar to the standard protocol established by the World Health Organisation for laboratory testing of mosquito larvicidal compounds [49]. Larvae were exposed to nine ammonia concentrations ranging from 5-2000 mg. $\mathrm{L}^{-1}$ total-N. Target concentrations were established by serial dilutions in distilled water starting from a commercial 5\% ammoniacal solution. Eight to twenty late-stage (III and IV instar) An. gambiae larvae from a single breeding site were placed individually in $10-\mathrm{mL}$ test tubes for each of the target concentrations. A control series containing only distilled water was established for each tested breeding site (total number of control larvae across tests: $n=412$ ). Larvae were not given access to food to avoid changes in the aquatic milieu. Isolation in individual tubes prevented cannibalism. Initially, larvae were scored at 12, 24, and 36 hours post-treatment, when they were considered dead if they could not dive or emerge at the water surface after touching with the tip of a pipette. Subsequently, for reasons presented below, mortality was scored after 12-hours exposure.

\section{Statistical analysis}

Because of sample size constraints, the total number of exposed and dead larvae from each group of localities (i.e. rural vs. urban sites) was pooled and used as the 


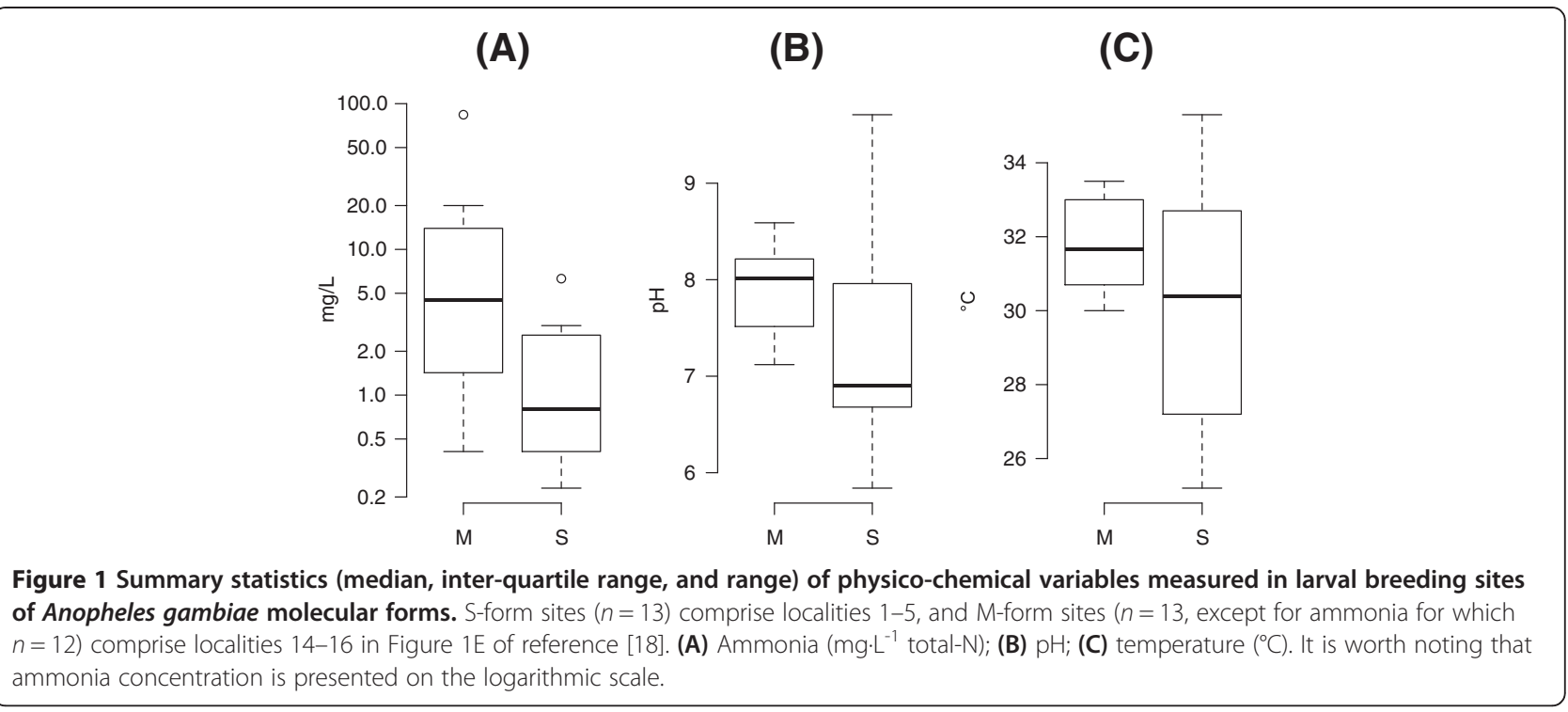

response variable in generalized linear models (GLMs) with a binomial errors structure, while ammonia concentration was fitted as the explanatory variable. Estimation of lethal concentrations (LC) followed a three-pronged approach. First, we explored the dependence of tolerance as a function of duration of exposure to the toxicant. To do so, we estimated the median lethal concentration $\left(\mathrm{LC}_{50}\right)$ at each exposure duration from the parameters of logistic regressions using a logit transformation. Because of the presence in some treatment combinations of substantial background mortality (i.e. the natural response occurring even in the absence of, or in addition to the toxicant, as evidenced from mortality in the control batches), we estimated regression parameters by maximum likelihood using custom-written functions in Mathematica v.7 (www.wolfram.com) following the approach described by Collett ([50], pp. 105-107).

Second, using the data set pertaining to 12-hours exposure we fitted with the statistical software $R$ v.2.13.0 (www.r-project.org) [51] several competing GLMs characterised by different combinations of link functions and scale of the explanatory variable (cf. Results below). As control mortality at this exposure interval was nil, this time it was not necessary to take into account and correct for the natural response. The minimal adequate models were identified by means of the Akaike information criterion (AIC). Standard errors for lethal concentrations were estimated with the function dose.p available in the MASS library.

Third, we used probit analysis to estimate the probability density function (PDF) of individual tolerance thresholds to assess their shape, variance, and degree of overlap among the two forms. In toxicity assays, probit analysis allows to relate the parameters of the regression line describing the dose-mortality relationship to a
Gaussian frequency distribution of tolerance thresholds in the population of individuals tested [50]. Under probit analysis, the median lethal concentration expresses the mean (mode), and the inverse of the slope of the regression line expresses the standard deviation of the normal distribution of tolerance thresholds. The ammonia concentrations corresponding to intersections of the PDFs of the $\mathrm{M}$ and $\mathrm{S}$ forms were estimated with an equation root-finding function in Mathematica.

Statistical inference for differences in the physicochemical variables was performed using non-parametric tests due to heteroscedasticity in these data.

\section{Results}

\section{Physico-chemical properties of natural larval habitats}

The median, inter-quartile range (IQR), and range of ammonia, $\mathrm{pH}$, and temperature measured in An. gambiae larval habitats are presented in Figure 1 . Ammonia $(P<0.02)$ and $\mathrm{pH}(P<0.05)$ were significantly higher in urban $\mathrm{M}$-form compared to rural S-form sites by the KruskalWallis rank sum test. Variation in ammonia concentration was significantly greater $(P<0.01)$ in urban $\mathrm{M}$-form sites by the Fligner-Killeen test. By the same test, temperature showed significantly greater variation $(P<0.05)$ in rural S-form sites (Figure 1).

\section{Dependence of tolerance on duration of ammonia exposure}

The median lethal concentration assessed by the preliminary regression analyses decreased with longer exposure to ammonia in the case of the $S$ form, but not for the $\mathrm{M}$ form (Figure 2). Average control mortality at 24 hours $(1.3 \%)$ was above zero but not significantly different $(P=0.25$ by Fisher's exact test) to that recorded 12 hours post-treatment $(0 \%)$, whereas 36 -hours mortality 
was significantly greater $(16.9 \%)$ than 24 -hours mortality $(P<0.0001$ by Fisher's exact test), and exceeded the $5 \%$ threshold marking the validity of a toxicity bioassay [49]. Accordingly, we present results based on scoring at 12 hours post-treatment, when control mortality was nil. This time lapse is shorter than that usually adopted by ecotoxicologists to assess ammonia tolerance in aquatic macro-invertebrates $[45,52]$. However, this interval provides the added benefit of minimizing evaporation, changes in $\mathrm{pH}$ (which is known to affect ammonia toxicity and tolerance levels), and changes in the physiological status of larvae due to starvation. Given the increased $\mathrm{LC}_{50}$ differential between the $\mathrm{M}$ and $\mathrm{S}$ forms with longer exposure (Figure 2), scoring mortality after 12 hours provided also a more conservative test for differences between molecular forms in ammonia tolerance.

\section{Assessment of lethal concentrations}

Of six competing GLMs fitted to the bioassay data, the one with ammonia concentration on the linear scale and a probit link function was minimal adequate for the $M$ form, and that with concentration on the logarithmic scale and a logit link function was minimal adequate for the $S$ form (Table 1). Major differences in the model explanatory power were observed mainly depending on the scale of the explanatory variable, i.e. either linear or logarithmic, whereas the differences between models

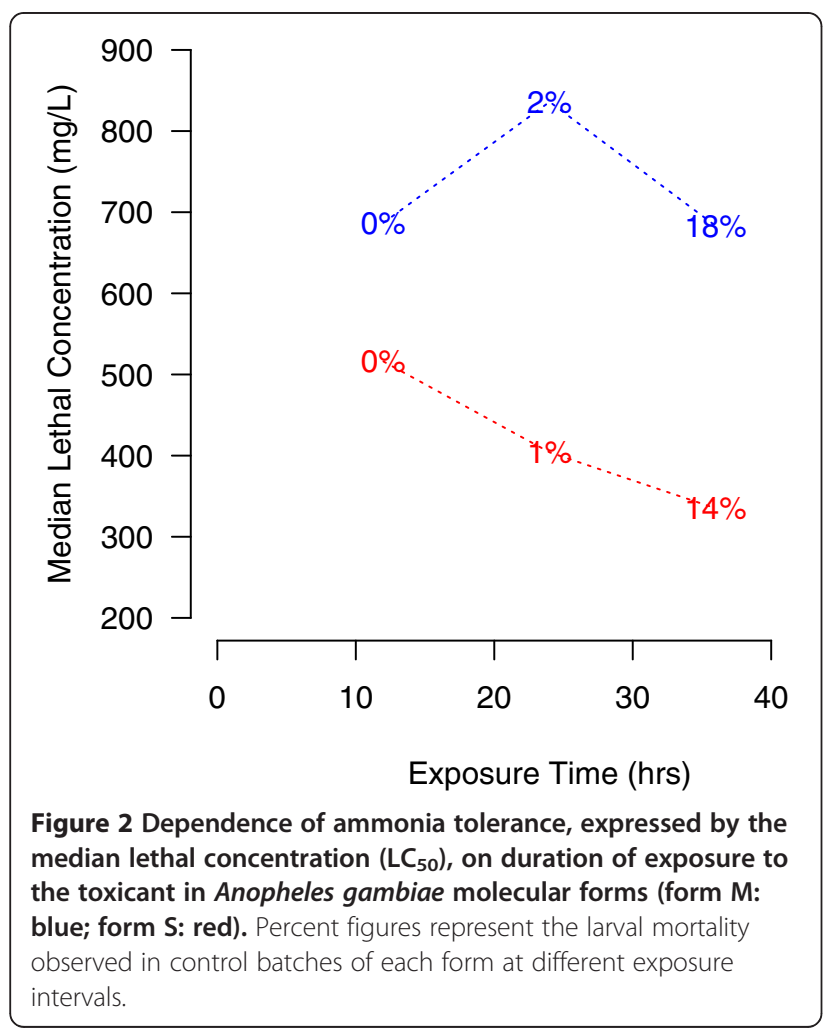

with different link functions were comparatively minor (Table 1). Accordingly, we used the minimal adequate models to estimate ammonia lethal concentrations (Table 2). The fitted curves describing the mortality response to ammonia concentration corresponding to the endpoints presented in Table 2 are shown in Figure 3A. Estimated median and 95\% lethal concentrations were higher in the $\mathrm{M}$ form compared to the $\mathrm{S}$ form. However, mortality was greater in the $M$ compared to the $S$ form at the low end of ammonia concentrations tested.

\section{Assessment of differences between forms in the dose- mortality response}

To verify whether the dose-mortality response was statistically different between the $\mathrm{M}$ and $\mathrm{S}$ forms-regardless of link function and scale for the explanatory variable-we compared the logistic regression models with a logit link function and ammonia concentration expressed on the same linear scale (Figure 3B), specifying a quasibinomial errors structure due to overdispersion in the data. Although arbitrary, this choice was justified on grounds that the residual deviance was similar in both the $\mathrm{M}$ and $\mathrm{S}$ forms for models having a logit link function and ammonia concentration expressed on the linear scale (Table 1). The relevant statistical test in this case is to verify whether the slope of the two regression lines characterising the dose-response relationship in the $\mathrm{M}$ and $\mathrm{S}$ forms is significantly different. Indeed, the slope of the regression line was significantly steeper for $\mathrm{S}$ sites compared to $\mathrm{M}$ sites (likelihood-ratio test: $\left.F_{1,14}=9.13 ; P<0.01\right)$, indicating that the $M$ form expressed higher phenotypic variability in ammonia tolerance compared to the $\mathrm{S}$ form (Figure $3 \mathrm{~B}$ ). However, the different slope of the dose-response relationship implies that a comparison of tolerances between the $M$ and $\mathrm{S}$ forms depends on the concentration considered. The superior performance of the $M$ form was apparent only at the higher range of concentrations tested. The higher phenotypic variability in ammonia tolerance exhibited by

Table 1 Akaike information criterion (AIC) of competing generalized linear models testing the effect of ammonia concentration on Anopheles gambiae molecular forms larval mortality

\begin{tabular}{lcccccc}
\hline Expl. & \multicolumn{6}{c}{ Molecular Form } \\
\cline { 2 - 7 } & \multicolumn{7}{c}{$\mathbf{M}$} & \multicolumn{5}{c}{$\mathbf{S}$} \\
\cline { 2 - 7 } & logit & probit & log-log & logit & probit & log-log \\
\hline CONC. & 60.26 & $\mathbf{5 9 . 2 3}$ & 59.24 & 55.71 & 55.59 & 107.29 \\
\hline $\log ($ CONC. $)$ & 141.41 & 166.22 & 108.86 & $\mathbf{2 7 . 4 2}$ & 27.73 & 33.62 \\
\hline
\end{tabular}

All models have a binomial errors structure but differ in the scale of the explanatory variable (CONC., i.e. ammonia concentration, linear vs. logtransformed), or the link function of the linear predictor (logit vs. probit vs. complementary log-log). The minimal adequate model for each taxon, i.e. that having the lowest AIC, is shown in bold. 
Table 2 Sample estimates of median ( $\left.\mathrm{LC}_{50}\right)$ and $95 \%$ ( $\left.L C_{95}\right)$ Lethal Concentrations ( $\pm 95 \%$ confidence limits) calculated from minimal adequate generalized linear models assessing the effect of ammonia concentration (expressed in $\mathrm{mg} \cdot \mathrm{L}^{-1}$ total-N) on Anopheles gambiae molecular forms larval mortality

\begin{tabular}{llccc}
\hline Form & \multicolumn{4}{c}{ Lethal Concentration (LC) } \\
\cline { 2 - 5 } & \multicolumn{3}{c}{$\mathbf{L C}_{\mathbf{5 0}}$} & \multicolumn{3}{c}{$\mathbf{L C}_{\mathbf{9 5}}$} \\
\hline $\mathrm{M}$ & 685 & $(639-729)$ & 1355 & $(1250-1460)$ \\
\hline $\mathrm{S}$ & 453 & $(421-486)$ & 1129 & $(986-1292)$ \\
\hline
\end{tabular}

The $\mathrm{LC}_{50}$ and $\mathrm{LC}_{95}$ presented in the table estimate the concentrations producing $50 \%$ and $95 \%$ mortality, respectively, in the larval population exposed for 12 hours to ammonia.

the $\mathrm{M}$ population indicates that this form had a larger variance in the distribution of individual tolerance thresholds, i.e. it comprised a greater proportion of individuals with a higher tolerance threshold compared to the $\mathrm{S}$ population.
This phenomenon can be seen more explicitly using the results of the GLMs with a probit link function. The two Gaussian curves describing the frequency distribution of individual tolerance thresholds for both the $\mathrm{M}$ and $\mathrm{S}$ forms are plotted in Figure 3C. The two curves, normal for the $\mathrm{M}$ form and lognormal for the $\mathrm{S}$ form, were parameterized using the results of the minimal adequate GLMs fitted with a probit link function. As shown by the two tolerance thresholds where the probability density functions for the $\mathrm{M}$ and $\mathrm{S}$ forms intersect (dotted lines in Figure $3 \mathrm{C}$ ), the $\mathrm{M}$ population had a greater frequency of individuals with tolerance thresholds $\geq 625 \mathrm{mg} \cdot \mathrm{L}^{-1}(\sim 56 \%$ versus $\sim 27 \%$ in the $S$ form), while the $S$ population had fewer individuals with tolerance thresholds $\leq 124 \mathrm{mg} \cdot \mathrm{L}^{-1}$ ( $1 \%$ versus $\sim 8 \%$ in the $\mathrm{M}$ form).

These figures help to understand the relative selective effects due to acute ammonia toxicity: a mixed population of 100 larvae of each form exposed to ammonia at $625 \mathrm{mg} \cdot \mathrm{L}^{-1}$ is expected to have twice as many $\mathrm{M}$-form

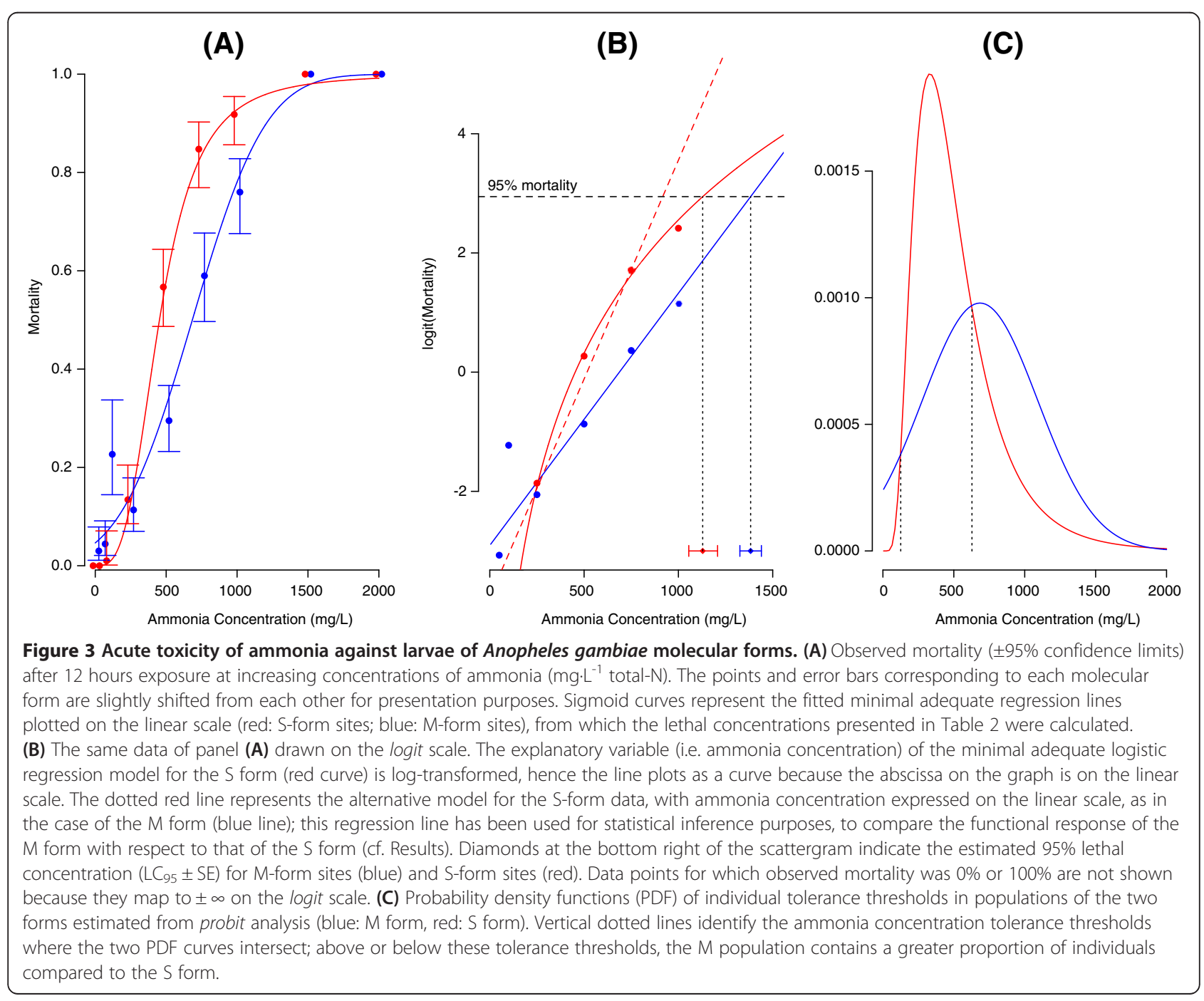


survivors (56 vs. 27, respectively). Conversely, at 124 $\mathrm{mg} \cdot \mathrm{L}^{-1}$, the $\mathrm{S}$-form survives slightly better $(99 \mathrm{~S}$-form against $92 \mathrm{M}$-form survivors) but there is a four-fold lower absolute difference (29vs. 7 , respectively). These ammonia concentrations correspond to tolerance thresholds for which the difference in survival between the two forms-in favour of the $M$ or the $S$ form, respectively-is maximised (figure not shown). Because the number of survivors is a function of ammonia concentration, however, the relative difference in survival between the two forms behaves somewhat differently. Figure 4 shows the ratio of $\mathrm{M}$-form survivors relative to $\mathrm{S}$-form survivors as a function of the culling ammonia concentration: at low concentrations the ratio remains below but close to unity, i.e. the number of $\mathrm{S}$-form survivors only slightly exceeds that of $\mathrm{M}$-form survivors (e.g. at $124 \mathrm{mg} \cdot \mathrm{L}^{-1}$, as seen previously, the ratio is $\sim 0.93$, which is close to the minimum ratio of 0.924 at 128 $\left.\mathrm{mg} \cdot \mathrm{L}^{-1}\right)$. Beyond $249 \mathrm{mg} \cdot \mathrm{L}^{-1}$, however, the ratio starts to increase steadily reaching a maximum at $1,031 \mathrm{mg} \cdot \mathrm{L}^{-1}$, when the number of $\mathrm{M}$-form survivors is three times (3.06-fold) that of S-form survivors (Figure 4). Beyond the maximum, the ratio decreases again towards unity as larval mortality approaches $100 \%$ in both forms. Increasing ammonia concentrations, therefore, will disproportionally select for $\mathrm{M}$-form survivors until concentrations are so high that no larva of either form can survive.

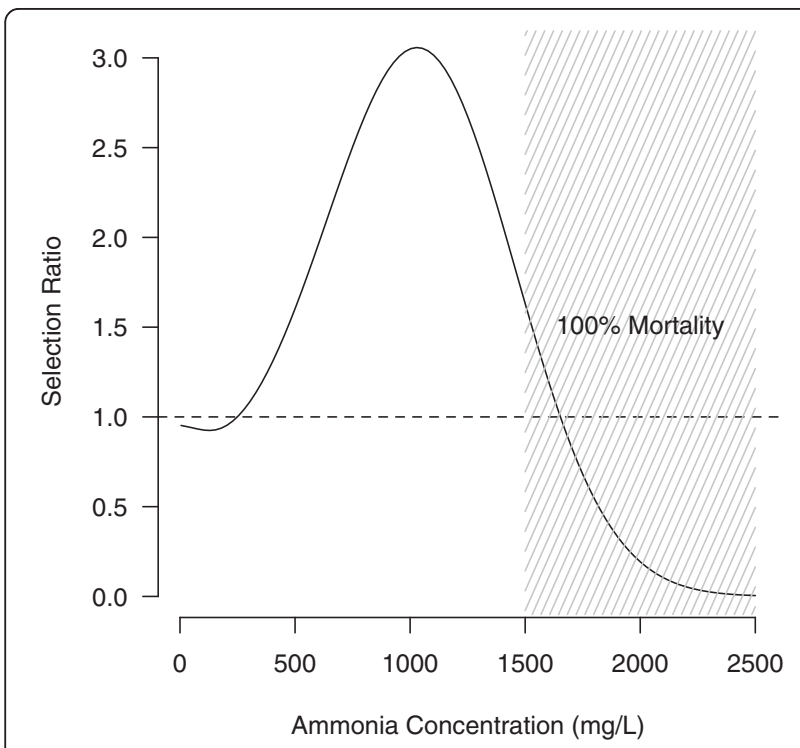

Figure 4 Estimated relative frequency of M-form vs. S-form survivors (Selection Ratio) when culling a mixed $\mathrm{M} / \mathrm{S}$ larval population using increasing ammonia concentrations. A Selection Ratio of one (horizontal dashed line) corresponds to equal numbers of $\mathrm{M}$ and $\mathrm{S}$ survivors. Values above this line identify the region where M-form survivors exceed S-form survivors, and vice versa for values below the line. Shading identifies the range of concentrations for which observed larval mortality was 100\% in both forms.

\section{Discussion}

In the rainforest of southern Cameroon ecological divergence between two molecular forms of the malaria mosquito Anopheles gambiae along urbanization gradients [18] is postulated to be the outcome of niche expansion by the $\mathrm{M}$ form, a process driven by disruptive selection and local adaptation to marginal habitats [17]. Historical records indicate that the core of highly urbanized settings constitute an unfavourable habitat for the persistence of $A n$. gambiae populations due to the paucity of suitable unpolluted water bodies necessary for the development of its aquatic larvae $[41,42,53,54]$. In the two major urban agglomerates of Cameroon, Yaounde and Douala [18], and in other large cities lying on the Gulf of Guinea [55-57], larvae of the M form appear to have evolved the ability to survive in polluted breeding sites. The physiological, behavioural, and other life-history traits that are involved in this process are, however, to date largely unknown. Starting from the observation that in the two major urban agglomerates of Cameroon the $\mathrm{M}$ form occurs at times in the same breeding sites of Culex quinquefasciatus [18], a mosquito pest which is notoriously abundant in waters enriched with nutrients, we postulated that the $M$ form might have developed enhanced tolerance to environmental stressors ensuing from the decomposition of organic matter.

Ammonia is a toxicant resulting from the decomposition of decaying organic matter often contaminating mosquito larval habitats [41,43,46,47,58,59]. Polluting human activities contribute to the generation and accumulation of this contaminant especially in unplanned urban environments in tropical Africa, where accessible water collections containing large amounts of decaying organic matter can be plentiful. Accordingly, by acute toxicity assays we have demonstrated quantitative differences in tolerance to ammonia between the urban population of the $\mathrm{M}$ form in Yaounde compared to the parapatric population of the $S$ form occurring in neighbouring rural settings. Higher ammonia tolerance in the $M$ form presumably constitutes an adaptive trait given that this toxicant occurred on average at higher concentration in An. gambiae urban larval habitats compared to rural ones. Moreover, urban breeding sites were on average more alkaline than rural ones, a physico-chemical property that enhances ammonia toxicity $[45,52]$. To confirm the adaptive value of tolerance, however, it will be necessary to demonstrate that individuals with greater ammonia tolerance have a higher relative fitness in the polluted larval habitats of the urban environment compared to individuals with lower tolerance. Additionally, it will be necessary to verify the heritable basis of ammonia tolerance demonstrated in other dipterans [60] to support the notion that disruptive selection has produced the quantitative differences between the $M$ and $S$ forms in this 
trait. Adaptive phenotypic differentiation can in fact also result from adaptive phenotypic plasticity without underlying genetic differentiation, which is a pre-requisite for local adaptation.

The quantitative differences that we have measured between the $\mathrm{M}$ and $\mathrm{S}$ forms concern mainly the shape and the variance, more than the mean, of the tolerance response. The $\mathrm{M}$ form exhibited a larger variance in the distribution of individual tolerances, whose consequence is that the $\mathrm{M}$ population comprised a greater proportion of individuals with a higher tolerance threshold compared to the $\mathrm{S}$ population. Under a mode of polygenic inheritance of ammonia tolerance, this pattern can be interpreted to be the outcome of several, not mutually exclusive, processes. First, greater variability in the distribution of thresholds could indicate that the $M$ form may have been subjected to relatively recent disruptive or directional selection for ammonia tolerance, in agreement with results from artificial selection experiments whereby the phenotypic variance of selected lines is generally increased [61]. Second, greater phenotypic variance is expected under selection with assortative mating [62]. If ammonia tolerance is selected along the urbanization gradient according to increasing selection intensities from the rural towards urban localities, on average individuals with greater tolerance will be selected for in the urban environment, and individuals with lower tolerance will be selected for in the rural environment. If mating occurs in the original environment before dispersal, this process will produce some assortative mating correlated to ammonia tolerance. The ensuing gametic-phase disequilibrium in loci influencing ammonia tolerance will result in increased additive genetic variance that will be reflected, if environmental and other genetic components of variance do not decrease, in greater phenotypic variance.

A concurrent interpretation hinges on the homogenising effect of gene flow, which counteracts diversification by selection during local adaptation [63]. Gene flow between the $\mathrm{M}$ and $\mathrm{S}$ molecular forms is strongly reduced but-apparently-not nil [64-66]. Asymmetric introgression of maladaptive alleles present in the rural S population into the urban $M$ population may hinder greater phenotypic divergence between the two forms, unless the genes underlying this phenotype are linked to genes controlling reproductive isolation between the two forms-a condition that would favour ecological speciation if ammonia tolerance is adaptive. Asymmetric introgression of $\mathrm{M}$-form nuclear genes into the $\mathrm{S}$-form genome (a pattern opposite to that predicted by our observations) has been demonstrated in Guinea Bissau, a relatively restricted geographical area of high hybridization between the two forms $[64,65]$. In a similar way, neighbouring demes of the larger M-form metapopulation occurring in forested southern Cameroon [18], connected by dispersal to the Yaounde deme, may introduce maladaptive tolerance alleles if these allochthonous demes do not share the same local adaptation mechanisms of the Yaounde deme. Maladaptive alleles would contribute towards greater phenotypic variance in tolerance thresholds observed in the Yaounde M population and could persist in the urban environment because of the presence of breeding sites with lower ammonia concentration, as indicated by the greater variance in ammonia concentration observed in urban compared to rural natural larval habitats.

In the context of recent niche expansion, it is relevant to ask whether the differences in ammonia tolerance observed between the $\mathrm{M}$ and $\mathrm{S}$ forms from Yaounde predate or are subsequent to the process of ecological divergence and local adaptation to the novel urban habitat. In the absence of historical data it is quite difficult to answer this question. The experimental designs typical of evolutionary toxicology, a discipline that investigates the impacts of environmental pollutants on the genetics of natural populations, include comparison of matched reference and polluted sites [67], which is the approach we have adopted in this study. However, any conclusion derived from this approach is confounded by the ancillary question of whether local adaptation to the urban environment predates or arose subsequent to initial lineage splitting between the molecular forms. Hints to answer these questions are likely to come from studies investigating the nature and degree of tolerance in other $\mathrm{M}$ and $\mathrm{S}$ geographical populations with varying exposures to naturally occurring pollutants. Despite the limitations of this correlational approach, a match between exposure and degree of tolerance in replicated demes will add credit to the hypothesis that increased tolerance has evolved in response to higher levels of contamination. Further hints will come from a more detailed understanding of the phylogeography of the $\mathrm{M}$ and $\mathrm{S}$ forms across their distribution range; ultimately, both approaches will shed light on the population structure and history of adaptations in An. gambiae.

The difference in ammonia tolerance observed between the $M$ and $S$ forms in Yaounde reflects a process of local adaptation whose generality and limits should be verified in other cities of their distribution range, particularly in regions where populations are akin genetically to those occurring in the rainforest eco-climatic zone of southern Cameroon (e.g. carrying homosequential standard karyotypes like the $\mathrm{M}$ and $\mathrm{S}$ populations in Yaounde [28]). It is already reported that in some West African cities in the savanna, An. arabiensis-another member of the An. gambiae sensu lato (s.l.) species complex-is extending its distribution southwards into urban environments $[68,69]$, and has developed the ability to breed in larval habitats contaminated by waste 
waters $[70,71]$. In East Africa, members of the An. gambiae s.l. complex occur in polluted urban larval habitats in Dar-es-Salaam [72], Kisumu, and Malindi [73]. These geographical differences outline the fact that adaptation to urban pollution is happening repeatedly and independently within the species complex, and it is presumably very recent given that urbanization is a relatively novel phenomenon; furthermore, they suggest that lineage splitting between the $\mathrm{M}$ and $\mathrm{S}$ forms predates adaptation to uban habitats, in agreement with the estimated age of their divergence that is situated well before the Neolithic revolution [74].

\section{Study caveats}

In our acute toxicity bioassays, the difference in tolerance between the two molecular forms appeared only at ammonia concentrations well above those measured in natural larval habitats in and around Yaounde. It must be noted, however, that the potency of a toxicant depends also on the duration of exposure, which in our case was the shortest usually employed by ecotoxicologists when testing ammonia tolerance of macro-invertebrates. Longer exposures usually engender lower lethal concentrations. In the case of the shrimp Litopenaeus vannamei, for example, the median lethal concentration of ammonia at 96 hours was approx. 33\% of that after 12 hours exposure [75]. From our preliminary analysis, the median lethal concentration after 36 hours exposure in the S form was $65 \%$ of that scored at 12 hours, and showed the same kind of decay with time observed in other invertebrates [75]. Nevertheless, we chose to score mortality after 12-hours exposure, and consequently shifted the range of test concentrations towards higherecologically less-relevant-values to avoid the influence of external factors like changes in $\mathrm{pH}$ or hunger, as evidenced by increased mortality in the control batches.

Ammonia tolerance, moreover, might reflect a general physiological response of detoxification and excretion following the same metabolic mechanisms involved in nitrogen homeostasis and osmoregulation [76]. Ammonia is one of several nitrogenous compounds that can be found in nutrient-enriched waters (e.g. those resulting from nitrification of organic matter, such as nitrites and nitrates, or fertilisers, such as urea), whose accumulative toxicity may act additively or synergistically with that due to ammonia [77]. Longer exposure to ammonia and other nitrogenous compounds in natural larval habitats might therefore select for a differential tolerance pattern between the $\mathrm{M}$ and $\mathrm{S}$ forms akin to that observed in our bioassays in response to short-term exposure to ammonia alone.

If differential tolerance to ammonia contributes to explain habitat segregation of the two molecular forms along the urbanization gradient in Yaounde, however, it is unlikely that it does so solely by selective effects engendered by acute toxicity. Sub-lethal or (sub-)chronic toxicity effects are also likely to operate in this context. It is not yet known, for example, how acute toxicity in $A n$. gambiae relates to chronic effects on life history traits affecting fitness. In Drosophila melanogaster, fruit-flies artificially selected for ammonia tolerance developed faster and expressed higher viability on ammonia-supplemented media [60]. The aim of this work was to highlight intrinsic physiological differences in tolerance between the $M$ and $\mathrm{S}$ forms in their response to toxic levels of ammonia rather than to assess the biopotency of ammonia or look at its chronic sub-lethal effects under longer exposure. This is a matter for future associative and experimental approaches once the ecological processes underlying the cline in the $\mathrm{M}$ and $\mathrm{S}$ populations abundance along urbanization gradients will be further clarified. Further, it is possible that local adaptation may be associated to differential responses not only to nitrogenous compounds, but also to other environmental stressors characteristic of An. gambiae breeding sites $[57,72,73,78,79]$, like temperature, organic and inorganic suspended solids, dissolved substances, emulsions and colloids (including e.g. heavy metals, detergents, oils, or other kinds of nutrients), or biological factors like micro-organisms [80], competitors [81-83], predators $[35,84]$, and their interactions (e.g. [85-87]); these effects need to be investigated at both the population and community level.

In this study we used late-instar larvae collected in the field to test for differential ammonia tolerance between the two molecular forms. Given the spatial segregation of the two forms along the urbanization gradient and the difference in average ammonia concentration between urban vs. rural breeding sites, the differences observed might have resulted from prior selection of more tolerant individuals in natural larval habitats before experimental exposure to ammonia in our bioassays. However, if the distribution of tolerance thresholds in the larval population before selection had been the same in both molecular forms, natural selection due to field exposure to greater concentrations of ammonia in the $\mathrm{M}$-form is expected to reduce the variance in tolerance, because only the more tolerant individuals would survive to the third- and fourth-instar stage of development. The fact that we actually observed greater-not reduced-variance in tolerance by the $M$ form is not consistent with this scenario, unless the distributions of ammonia concentrations in urban vs. rural larval habitats largely overlapped in the lower range of concentrations, an outcome not manifest in our test samples (cf. Figure 1). Future ammonia tolerance bioassays performed on F2 progeny of field-collected mosquitoes could help resolve this issue and avoid further confounding factors due to maternal effects. 
Despite the limitations of this study, it is clear that ecological divergence between the two molecular forms of An. gambiae in Yaounde is associated to differences in a physiological response that potentially affect the survival of larvae in natural breeding sites. Development of tolerance may engender costs leading to trade-offs in other fitness-related life-history traits, as observed for East African populations of An. gambiae in response to increased tolerance to heavy metals [88]. We speculate, therefore, that development of ammonia tolerance might have fostered niche expansion into the urban environment by forest populations of the $\mathrm{M}$ form in Yaounde, while also conferring a competitive disadvantage in the unpolluted larval habitats typical of rural settings in the rainforest block of Cameroon.

\section{Conclusions}

Increased tolerance to pollutants in An. gambiae s.l. which is associated with its adaptation to live in densely populated urban environments, bears important potential epidemiological consequences on parasite transmission. If selection for adaptive mechanisms will increase the mean fitness of urban populations, it is conceivable that in the future vector densities and/or survival may increase in densely populated urban environments, a process that would ultimately increase the vectorial capacity of these important malaria vectors. Human population growth projections estimate that, by year $2050,>60 \%$ of the population in Western and Central Africa will live in urban areas, against the current $~ 40 \%$ figure and the past $\sim 10 \%$ figure in 1950 [89]. Given these emerging trends, therefore, urban transmission is likely to hold an increasingly prominent place in malaria epidemiology, compared to the present situation [90-92]. Moreover, exposure to pollutants and xenobiotics in urban larval habitats may foster the evolution of insecticide resistance $[46,47,71,78]$, thereby compromising our capacity to combat harmful vector-borne diseases like malaria, lymphatic filariasis, or Anopheles-transmitted arboviruses. It remains to be seen how the costs associated with increased tolerance may affect other fitnessrelated traits, e.g. fertility, fecundity or parasite competence. It is only by means of studies investigating the impact of increased tolerance to pollutants on lifehistory traits affecting fitness that it will be possible to achieve more accurate predictions about the consequences of An. gambiae s.l. adaptation to urban environments on vectorial capacity.

\footnotetext{
Abbreviations

AIC: Akaike information criterion; F2: Second generation; GLM: Generalized linear model; LC: Lethal concentration; PCR: Polymerase chain reaction; PDF: Probability density function; RFLP: Restriction fragment length polymorphism; sl: Sensu lato.
}

\section{Competing interests}

The authors declare no competing interests.

\section{Authors' contributions}

CC, NJB initiated and designed the study. CAN, FN co-ordinated and supervised lab and field work. BTF, CAN performed field work. BTF, PK processed specimens, carried out biological and chemical assays and molecular analyses. CC, BTF carried out statistical analyses and drafted the paper. NJB, CAN, FN, PK critically revised the manuscript. All authors read and approved the final manuscript.

\section{Acknowledgements}

Our gratitude goes to the staff of the OCEAC Malaria Research Laboratory, with particular reference to Jean-Pierre Agbor, Roger Beyene, Serge Donfack, Sylvie Kemleu, and Etienne Onana for technical assistance, and Colince Kamdem, Parfait Awono-Ambene, and Isabelle Morlais for their help during the course of this work. We acknowledge three anonymous reviewers whose comments contributed to improve the manuscript. Financial support was provided by IRD, NIH grant N R01 Al63508 to NJB, and Wellcome Trust Intermediate Fellowship in Public Health and Topical Medicine $\mathrm{N}^{\circ}$ WT086423MA to CAN.

In memoriam of Prof. Mario Coluzzi (1938-2012).

\section{Author details}

${ }^{1}$ Institut de Recherche pour le Développement (IRD), Unité Mixte de Recherche MIVEGEC (UM1, UM2, CNRS 5290, IRD 224), Montpellier, France. ${ }^{2}$ Laboratoire de Recherche sur le Paludisme, Organisation de Coordination pour la lutte contre les Endémies en Afrique Centrale (OCEAC), Yaounde, Cameroon. ${ }^{3}$ Faculty of Sciences, University of Yaounde I, Yaounde, Cameroon. ${ }^{4}$ Department of Biological Sciences, Eck Institute for Global Health, University of Notre Dame, Notre Dame, IN, USA.

Received: 30 July 2012 Accepted: 27 December 2012 Published: 7 January 2013

\section{References}

1. Holt RD, Gaines MS: Analysis of adaptation in heterogeneous landscapes: implications for the evolution of fundamental niches. Evolutionary Ecology 1992, 6(5):433-447.

2. Hoffmann AA: Physiological climatic limits in Drosophila: patterns and implications. J Exp Biol 2010, 213(6):870-880.

3. Normand S, Treier UA, Randin C, Vittoz P, Guisan A, Svenning J-C: Importance of abiotic stress as a range-limit determinant for European plants: insights from species responses to climatic gradients. Glob Ecol Biogeogr 2009, 18(4):437-449.

4. Hoffmann AA, Parsons PA: Extreme environmental change and evolution. Cambridge: Cambridge University Press; 1997.

5. Bradshaw WE, Holzapfel CM: Climate change. evolutionary response to rapid climate change. Science 2006, 312(5779):1477-1478.

6. Tomanek L: Variation in the heat shock response and its implication for predicting the effect of global climate change on species' biogeographical distribution ranges and metabolic costs. J Exp Biol 2010, 213(6):971-979.

7. Sørensen JG, Norry FM, Scannapieco AC, Loeschcke V: Altitudinal variation for stress resistance traits and thermal adaptation in adult Drosophila buzzatii from the New World. J Evol Biol 2005, 18(4):829-837.

8. Liefting M, Hoffmann AA, Ellers J: Plasticity versus environmental canalization: population differences in thermal responses along a latitudinal gradient in Drosophila serrata. Evolution 2009, 63(8):1954-1963.

9. Sisodia S, Singh BN: Resistance to environmental stress in Drosophila ananassae: latitudinal variation and adaptation among populations. J Evol Biol 2010, 23(9):1979-1988.

10. Fouet C, Gray E, Besansky NJ, Costantini C: Adaptation to aridity in the malaria mosquito Anopheles gambiae: chromosomal inversion polymorphism and body size influence resistance to desiccation. PLoS One 2012, 7(4):e34841.

11. Parkash R, Rajpurohit S, Ramniwas S: Changes in body melanisation and desiccation resistance in highland vs. lowland populations of D. melanogaster. J Insect Physiol 2008, 54(6):1050-1056. 
12. Bridle JR, Gavaz S, Kennington WJ: Testing limits to adaptation along altitudinal gradients in rainforest Drosophila. Proc R Soc Ser B 2009, 276(1661):1507-1515.

13. Schlesinger MD, Manley PN, Holyoak M: Distinguishing stressors acting on land bird communities in an urbanizing environment. Ecology 2008, 89(8):2302-2314

14. Ning NSP, Nielsen DL, Baldwin DS: Assessing the potential for biotic communities to recolonise freshwater wetlands affected by sulfidic sediments. Freshwater Biol 2011, 56(11):2299-2315.

15. Kefford BJ, Hickey GL, Gasith A, Ben-David E, Dunlop JE, Palmer CG, Allan K, Choy SC, Piscart C: Global scale variation in the salinity sensitivity of riverine macroinvertebrates: Eastern Australia, France, Israel and South Africa. Plos One 2012, 7(5):e35224.

16. Macnair M: Heavy-metal tolerance in plants - a model evolutionary system. Trends Ecol Evol 1987, 2(12):354-359.

17. Costantini C, Ayala D, Guelbeogo WM, Pombi M, Some CY, Bassole $\mathrm{H}_{\text {, Ose }}$ K, Fotsing J-M, Sagnon NF, Fontenille D, et al: Living at the edge: biogeographic patterns of habitat segregation conform to speciation by niche expansion in Anopheles gambiae. BMC Ecol 2009, 9:16.

18. Kamdem C, Tene-Fossog B, Simard F, Etouna J, Ndo C, Kengne $P$, Boussès $P$, Etoa F-X, Awono-Ambene P, Fontenille D, et al: Anthropogenic habitat disturbance and ecological divergence between incipient species of the malaria mosquito Anopheles gambiae. PLoS One 2012, 7(6):e39453.

19. della Torre A, Costantini C, Besansky NJ, Caccone A, Petrarca V, Powell JR, Coluzzi M: Speciation within Anopheles gambiae-the glass is half full. Science 2002, 298(5591):115-117.

20. White BJ, Collins FH, Besansky NJ: Evolution of Anopheles gambiae in relation to humans and malaria. Annu Rev Ecol Evol Syst 2011, 42:111-132.

21. Ayala FJ, Coluzzi M: Chromosome speciation: humans, Drosophila, and mosquitoes. Proc Natl Acad Sci U S A 2005, 102(Suppl 1):6535-6542.

22. Slotman MA, Reimer LJ, Thiemann T, Dolo G, Fondjo E, Lanzaro GC: Reduced recombination rate and genetic differentiation between the $M$ and S forms of Anopheles gambiae S.s. Genetics 2006, 174(4):2081-2093.

23. Slotman MA, Tripet F, Cornel AJ, Meneses CR, Lee $Y$, Reimer $L$, Thiemann TC, Fondjo E, Fofana A, Traore SF, et al: Evidence for subdivision within the M molecular form of Anopheles gambiae. Mol Ecol 2007, 16(3):639-649.

24. Neafsey DE, Lawniczak MK, Park DJ, Redmond SN, Coulibaly MB, Traore SF, Sagnon N, Costantini C, Johnson C, Wiegand RC, et al: SNP genotyping defines complex gene-flow boundaries among African malaria vector mosquitoes. Science 2010, 330(6003):514-517.

25. della Torre A, Tu Z, Petrarca V: On the distribution and genetic differentiation of Anopheles gambiae s.s. molecular forms. Insect Biochem Mol Biol 2005, 35(7):755-769.

26. Sogoba N, Vounatsou P, Bagayoko MM, Doumbia S, Dolo G, Gosoniu L, Traore SF, Smith TA, Toure YT: Spatial distribution of the chromosomal forms of Anopheles gambiae in Mali. Malar J 2008, 7:205.

27. Caputo B, Nwakanma D, Jawara M, Adiamoh M, Dia I, Konate L, Petrarca V, Conway DJ, della Torre A: Anopheles gambiae complex along The Gambia river, with particular reference to the molecular forms of An. gambiae s.s. Malar J 2008, 7:182.

28. Simard F, Ayala D, Kamdem GC, Pombi M, Etouna J, Ose K, Fotsing JM, Fontenille D, Besansky NJ, Costantini C: Ecological niche partitioning between Anopheles gambiae molecular forms in Cameroon: the ecological side of speciation. BMC Ecol 2009, 9:17.

29. Coluzzi M, Petrarca V, Di Deco MA: Chromosomal inversion intergradation and incipient speciation in Anopheles gambiae. Boll Zool 1985, 52:45-63.

30. Yawson AE, Weetman D, Wilson MD, Donnelly MJ: Ecological zones rather than molecular forms predict genetic differentiation in the malaria vector Anopheles gambiae s.s. in Ghana. Genetics 2007, 175(2):751-761.

31. Lee $Y$, Cornel AJ, Meneses CR, Fofana A, Andrianarivo AG, McAbee RD, Fondjo E, Traore SF, Lanzaro GC: Ecological and genetic relationships of the Forest-M form among chromosomal and molecular forms of the malaria vector Anopheles gambiae sensu stricto. Malar J 2009, 8:75.

32. Huestis DL, Yaro AS, Traore Al, Dieter KL, Nwagbara Jl, Bowie AC, Adamou A Kassogue $Y$, Diallo M, Timbine $S$, et al: Seasonal variation in metabolic rate, flight activity and body size of Anopheles gambiae in the Sahel. J Exp Biol 2012, 215(Pt 12):2013-2021.

33. Yaro AS, Traore Al, Huestis DL, Adamou A, Timbine S, Kassogue Y, Diallo M, Dao A, Traore SF, Lehmann T: Dry season reproductive depression of Anopheles gambiae in the Sahel. J Insect Physiol 2012, 58(8):1050-1059.
34. Gimonneau G, Pombi M, Choisy M, Morand S, Dabire RK, Simard F: Larval habitat segregation between the molecular forms of the mosquito Anopheles gambiae in a rice field area of Burkina Faso, West Africa. Med Vet Entomol 2012, 26(1):9-17.

35. Diabate A, Dabire RK, Heidenberger K, Crawford J, Lamp WO, Culler LE, Lehmann T: Evidence for divergent selection between the molecular forms of Anopheles gambiae: role of predation. BMC Evol Biol 2008, 8:5.

36. Antonio-Nkondjio C, Simard F, Awono-Ambene PH, Ngassam P, Toto J-C, Tchuinkam T, Fontenille D: Malaria vectors and urbanization in the equatorial forest region of south Cameroon. Trans $R$ Soc Trop Med Hyg 2005, 99(5):347-354.

37. Afrane YA, Zhou G, Lawson BW, Githeko AK, Yan G: Effects of microclimatic changes caused by deforestation on the survivorship and reproductive fitness of Anopheles gambiae in western Kenya highlands. Am J Trop Med Hyg 2006, 74(5):772-778.

38. Vittor AY, Gilman RH, Tielsch J, Glass G, Shields T, Lozano WS, PinedoCancino V, Patz JA: The effect of deforestation on the human-biting rate of Anopheles darlingi, the primary vector of Falciparum malaria in the Peruvian Amazon. Am J Trop Med Hyg 2006, 74(1):3-11.

39. Subra R: Biology and control of Culex pipiens quinquefasciatus Say, 1823 (Diptera, Culicidae) with special reference to Africa. Insect Sci App/ 1981, 1(4):319-338.

40. Rageau J, Adam J-P, Rivola E: Etude préliminaire sur la biologie d'Anopheles gambiae, Giles 1902 dans les régions forestières du SudCameroun. Annales de Parasitologie 1953, 28(5-6):425-449.

41. Doby J, Mouchet J: Écologie larvaire de quelques espèces de Culicidés dans la région de Yaoundé (Sud-Cameroun). Bull Soc Pathol Exot 1957, 50(6):945-957

42. Trape JF, Zoulani A: Malaria and urbanization in central Africa: the example of Brazzaville. Part II: Results of entomological surveys and epidemiological analysis. Trans R Soc Trop Med Hyg 1987, 81(Suppl. 2):10-18.

43. Sinha V: Further observations on the physico-chemical factors of the breeding places of Culex quinquefasciatus Say = fatigans Wied. Mosq News 1976, 36(3):358-360.

44. Wiesmann U, Choi IS, Dombrowski E-M: Fundamentals of biological wastewater treatment. Weinheim: Wiley-VCH Verlag GmbH \& Co. KGaA; 2007.

45. Environmental Protection Agency: Draft 2009 update. Aquatic life ambient water quality criteria for ammonia - freshwater. Washington, DC: United States Environmental Protection Agency; 2009.

46. Antonio-Nkondjio C, Fossog BT, Ndo C, Djantio BM, Togouet SZ, AwonoAmbene P, Costantini C, Wondji CS, Ranson H: Anopheles gambiae distribution and insecticide resistance in the cities of Douala and Yaoundé (Cameroon): influence of urban agriculture and pollution. Malar J 2011, 10:154.

47. Tene Fossog B, Kopya E, Ndo C, Menze-Djantio B, Costantini C, Njiokou F, Awono-Ambene P, Antonio-Nkondjio C: Water quality and Anopheles gambiae larval tolerance to pyrethroids in the cities of Douala and Yaoundé (Cameroon). J Trop Med 2012, 2012:1-10.

48. Fanello C, Santolamazza F, della Torre A: Simultaneous identification of species and molecular forms of the Anopheles gambiae complex by PCR-RFLP. Med Vet Entomol 2002, 16(4):461-464.

49. WHO: Guidelines for laboratory and field testing of mosquito larvicides. Geneva: World Health Organization; 2005.

50. Collett D: Modelling binary data. Boca Raton: Chapmann \& Hall/CRC; 1999.

51. R Development Core Team: $R$ : a language and environment for statistical computing. Vienna, Austria: R Foundation for Statistical Computing; 2009.

52. Canadian Council of Ministers of the Environment: Canadian water quality guidelines for the protection of aquatic life: Ammonia. Canadian environmental quality guidelines, 1999. Winnipeg: Canadian Council of Ministers of the Environment; 2010.

53. Coene J: Malaria in urban and rural Kinshasa: the entomological input. Med Vet Entomol 1993, 7(2):127-137

54. Machault V, Vignolles C, Pagès F, Gadiaga L, Gaye A, Sokhna C, Trape J-F, LacauX J-P, Rogier C: Spatial heterogeneity and temporal evolution of malaria transmission risk in Dakar, Senegal, according to remotely sensed environmental data. Malar J 2010, 9:252.

55. Chinery WA: Effects of ecological changes on the malaria vectors Anopheles funestus and the Anopheles gambiae complex of mosquitos in Accra, Ghana. J Trop Med Hyg 1984, 87(2):75-81.

56. Kristan M, Fleischmann H, della Torre A, Stich A, Curtis CF: Pyrethroid resistance/susceptibility and differential urban/rural distribution of 
Anopheles arabiensis and An. gambiae s.s. malaria vectors in Nigeria and Ghana. Med Vet Entomol 2003, 17(3):326-332.

57. Awolola TS, Oduola AO, Obansa JB, Chukwurar NJ, Unyimadu JP: Anopheles gambiae s.s. breeding in polluted water bodies in urban Lagos, southwestern Nigeria. J Vector Borne Dis 2007, 44(4):241-244.

58. Carpenter SR: Stemflow chemistry: effects on population dynamics of detritivorous mosquitos in tree-hole ecosystems. Oecologia 1982, 53(1):1-6.

59. Darriet F, Corbel V: Attractive properties and physicochemical modifications of water following colonization by Aedes aegypti larvae (Diptera: Culicidae). Comptes Rendus Biologies 2008, 331(8):617-622.

60. Borash D, Pierce V, Gibbs A, Mueller L: Evolution of ammonia and urea tolerance in Drosophila melanogaster: resistance and cross-tolerance. J Insect Physiol 2000, 46(5):763-769.

61. Falconer DS: Introduction to Quantitative Genetics. 3rd edition. Harlow, Essex, UK: Longman Scientific \& Technical; 1989.

62. Tallis GM, Leppard P: The joint effects of selection and assortative mating on a single polygenic character. Theor Appl Genet 1987, 75:41-45.

63. Kawecki T, Ebert D: Conceptual issues in local adaptation. Ecol Lett 2004, 7(12):1225-1241.

64. Marsden CD, Lee Y, Nieman CC, Sanford MR, Dinis J, Martins C, Rodrigues A, Cornel AJ, Lanzaro GC: Asymmetric introgression between the $\mathrm{M}$ and $\mathrm{S}$ forms of the malaria vector, Anopheles gambiae, maintains divergence despite extensive hybridization. Mol Ecol 2011, 20(23):4983-4994.

65. Weetman D, Wilding CS, Steen K, Pinto J, Donnelly MJ: Gene flowdependent genomic divergence between Anopheles gambiae $\mathrm{M}$ and $\mathrm{S}$ forms. Mol Biol Evol 2012, 29(1):279-291.

66. Reidenback KR, Neafsey DE, Costantini C, Sagnon N, Simard F, Ragland GJ, Egan SP, Feder JL, Muskavitch MAT, Besansky NJ: Patterns of genomic differentiation between ecologically differentiated $\mathrm{M}$ and $\mathrm{S}$ forms of Anopheles gambiae in West And Central Africa. Genome Biol Evol 2012, 4(12):1202-1212.

67. Bickham JW: The four cornerstones of evolutionary toxicology. Ecotoxicology 2011, 4(12):1202-1212.

68. Djogbenou L, Pasteur N, Bio-Bangana S, Baldet T, Irish SR, Akogbeto M, Weill $\mathrm{M}$, Chandre F: Malaria vectors in the Republic of Benin: distribution of species and molecular forms of the Anopheles gambiae complex. Acta Trop 2010, 114(2):116-122.

69. Dabire RK, Namountougou M, Sawadogo SP, Yaro LB, Toe HK, Ouari A Gouagna LC, Simard F, Chandre F, Baldet T, et al: Population dynamics of Anopheles gambiae s.l. in Bobo-Dioulasso city: bionomics, infection rate and susceptibility to insecticides. Parasites Vectors 2012, 5:127.

70. Fournet F, Cussac M, Ouari A, Meyer PE, Toe HK, Gouagna LC, Dabire RK: Diversity in anopheline larval habitats and adult composition during the dry and wet seasons in Ouagadougou (Burkina Faso). Malar J 2010, 9:78.

71. Jones CM, Toe HK, Sanou A, Namountougou M, Hughes A, Diabate A, Dabire R, Simard F, Ranson $\mathrm{H}$ : Additional selection for insecticide resistance in urban malaria vectors: DDT resistance in Anopheles arabiensis from Bobo-Dioulasso, Burkina Faso. PLoS One 2012, 7(9):e45995.

72. Sattler MA, Mtasiwa D, Kiama M, Premji Z, Tanner M, Killeen GF, Lengeler C: Habitat characterization and spatial distribution of Anopheles sp. mosquito larvae in Dar es Salaam (Tanzania) during an extended dry period. Malar J 2005, 4:4

73. Mireji PO, Keating J, Hassanali A, Mbogo CM, Nyambaka H, Kahindi S, Beier JC: Heavy metals in mosquito larval habitats in urban Kisumu and Malindi, Kenya, and their impact. Ecotoxicol Environ Saf 2008 70(1):147-153.

74. Crawford JE, Lazzaro B: The demographic histories of the $\mathrm{M}$ and $\mathrm{S}$ molecular forms of Anopheles gambiae s.s. Mol Biol Evol 2010, 27(8):1739-1744.

75. Lin $Y$, Chen J: Acute toxicity of ammonia on Litopenaeus vannamei Boone juveniles at different salinity levels. J Exp Mar Biol Ecol 2001, 259(1):109-119.

76. Wright PA: Nitrogen excretion: three end products, many physiological roles. J Exp Biol 1995, 198(Pt 2):273-281.

77. Camargo JA, Alonso A: Ecological and toxicological effects of inorganic nitrogen pollution in aquatic ecosystems: A global assessment. Environ Int 2006, 32(6):831-849.

78. Djouaka RF, Bakare AA, Bankole HS, Doannio JM, Coulibaly ON, Kossou H, Tamo M, Basene HI, Popoola OK, Akogbeto MC: Does the spillage of petroleum products in Anopheles breeding sites have an impact on the pyrethroid resistance? Malar J 2007, 6:159.
79. Bayoh MN, Lindsay SW: Temperature-related duration of aquatic stages of the Afrotropical malaria vector mosquito Anopheles gambiae in the laboratory. Med Vet Entomol 2004, 18(2):174-179.

80. Boissiere A, Tchioffo MT, Bachar D, Abate L, Marie A, Nsango SE, Shahbazkia HR, Awono-Ambene PH, Levashina EA, Christen R, et al: Midgut microbiota of the malaria mosquito vector Anopheles gambiae and interactions with Plasmodium falciparum infection. PLoS Pathog 2012, 8(5):e1002742.

81. Kweka EJ, Zhou G, Beilhe LB, Dixit A, Afrane Y, Gilbreath TM 3rd, Munga S, Nyindo M, Githeko AK, Yan G: Effects of co-habitation between Anopheles gambiae s.s. and Culex quinquefasciatus aquatic stages on life history traits. Parasites Vectors 2012, 5:33.

82. Koenraadt CJ, Takken W: Cannibalism and predation among larvae of the Anopheles gambiae complex. Med Vet Entomol 2003, 17(1):61-66.

83. Schneider P, Takken W, McCall PJ: Interspecific competition between sibling species larvae of Anopheles arabiensis and An. gambiae. Med Vet Entomol 2000, 14(2):165-170.

84. Kweka EJ, Zhou G, Gilbreath TM 3rd, Afrane Y, Nyindo M, Githeko AK, Yan G: Predation efficiency of Anopheles gambiae larvae by aquatic predators in western Kenya highlands. Parasites Vectors 2011, 4:128.

85. Heugens EH, Hendriks AJ, Dekker T, van Straalen NM, Admiraal W: A review of the effects of multiple stressors on aquatic organisms and analysis of uncertainty factors for use in risk assessment. Crit Rev Toxicol 2001, 31(3):247-284

86. Holmstrup M, Bindesbøl A-M, Oostingh GJ, Duschl A, Scheil V, Köhler H-R, Loureiro S, Soares AMVM, Ferreira ALG, Kienle C, et al: Interactions between effects of environmental chemicals and natural stressors: a review. Sci Total Environ 2010, 408(18):3746-3762.

87. Kirby MJ, Lindsay SW: Effect of temperature and inter-specific competition on the development and survival of Anopheles gambiae sensu stricto and An. arabiensis larvae. Acta Trop 2009, 109(2):118-123.

88. Mireji PO, Keating J, Hassanali A, Mbogo CM, Muturi MN, Githure Jl, Beier JC: Biological cost of tolerance to heavy metals in the mosquito Anopheles gambiae. Med Vet Entomol 2010, 24(2):101-107.

89. United Nations: World Urbanization Prospects: the 2011 Revision. New York: CD-ROM edn; 2012.

90. Robert V, Maclntyre K, Keating J, Trape J-F, Duchemin J-B, Warren M, Beier JC: Malaria transmission in urban sub-Saharan Africa. Am J Trop Med Hyg 2003, 68(2):169-176.

91. Hay SI, Guerra CA, Tatem AJ, Atkinson PM, Snow RW: Urbanization, malaria transmission and disease burden in Africa. Nat Rev Microbiol 2005, 3(1):81-90.

92. Donnelly MJ, McCall PJ, Lengeler C, Bates I, D'Alessandro U, Barnish G, Konradsen F, Klinkenberg E, Townson H, Trape JF, et al: Malaria and urbanization in sub-Saharan Africa. Malar J 2005, 4(1):12

doi:10.1186/1472-6785-13-1

Cite this article as: Tene Fossog et al:: Physiological correlates of ecological divergence along an urbanization gradient: differential tolerance to ammonia among molecular forms of the malaria mosquito Anopheles gambiae. BMC Ecology 2013 13:1.

\section{Submit your next manuscript to BioMed Central and take full advantage of:}

- Convenient online submission

- Thorough peer review

- No space constraints or color figure charges

- Immediate publication on acceptance

- Inclusion in PubMed, CAS, Scopus and Google Scholar

- Research which is freely available for redistribution 